\title{
Phytochemical Analysis and Antibacterial Determination of Costus Igneus Leaves
}

\author{
Sapna Patil, Malika Ahuja \\ Department of Biotechnology, B.N.N. College of Arts, Science and Commerce, Bhiwandi, Maharashtra, India
}

\begin{abstract}
How to cite this paper: Sapna Patil | Malika Ahuja "Phytochemical Analysis and Antibacterial Determination of Costus Igneus Leaves" Published in International Journal of Trend in Scientific Research and Development (ijtsrd), ISSN: 24566470, Volume-3 | Issue-3, April 2019, pp. 108-110. http://www.ijtsrd.co $\mathrm{m} /$ papers/ijtsrd216 54.pdf

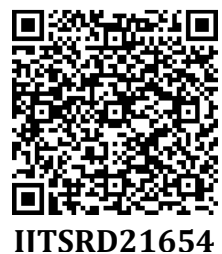

Copyright (C) 2019 by author(s) and International Journal of Trend in Scientific Research and Development Journal. This is an Open Access article distributed under the terms of the Creative Commons

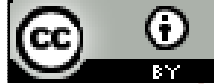
Attribution License (CC BY 4.0) (http://creativecommons.org/licenses/ by $/ 4.0$ )

\section{INTRODUCTION}

Plant used in traditional medicine may comprise a substantial source of modern biologically activity compound. Costus igneus common name fiery costs or spiral slag is an herbaceous belong to cetacean family. It is a delicious perennial herb, enlarging to $2.7 \mathrm{~m}$ tall and having erect stem the plant reproduces vegetative through rhizomes or seeds dispel by bird (Vinayaka et.al.2011). They are greyish green stained with red purple atop darker purple below the teeny white flowers grow occasionally throughout the year. It is specially on the higher new entrant to Kerala and India (Ramya et.al.2015). The plant extracts have been developed and proposed for use as antimicrobial substance. The antibacterial activities of medical plants can be attributed to the secondary metabolites such as alkaloids, flavonoids, tannins, terpenoid that are present in this plant. In the recent year, secondary plant metabolites (photochemical), previously with unknow pharmacological activities have been intensively investigated as a source of medical plants. Thus, it is anticipated that phytochemical with adequate bacterial efficacy will used for the bacterial infection (Vasantharaj et.al., 2013).

\section{MATERIAL AND METHOD}

Collection of sample

Mature leaves of Costus igneus were collected from Titwala garden in Kalyan.

\section{ABSTRACT}

Costus igneus belongs to the Costaceae family. Costus igneus common name is 'Fiery Costus' or 'Spiral Flag', is a species of herbaceous plant in the Costaceae family Costus igneus is traditionally know as insulin plant in Maharashtra. In dia it is grow in garden as ornamental plant. This plant is becoming popular basic analytical value for Costus igneus leaf powder. Identification of the secondary metabolites from Costus igneus plant in therapeutic application of

KEYWORDS: Costus igneus; phytochemical; anti-bacterial

\section{Processing of sample}

All leaves were washed under tap water separately in batches and shade dried for seven to ten days. After drying leaves were processed in powdered using electric grinder and stored in airtight container.

Preparation of leaf extract with aqueous solution

For Cold extract, $2 \mathrm{gm}$ of leaf powder was added to $20 \mathrm{~mL}$ of distilled water and stirred it constantly for half an hour. This mixture was kept at room temperature for 24 hours. Followed by filtration through Whatman filter paper no.1 For Hot extract, $1 \mathrm{gm}$ of leaf powder was added to $20 \mathrm{~mL}$ of distilled water and stirred it constantly for half an hour. This mixture was kept at room temperature for 24 hour. The solution was then boiled at $100^{\circ} \mathrm{C}$ to make hot extract followed by filtration through Whatman filter paper no.1

\section{Phytochemical analysis of hot aqueous leaf extract of Costus igneus \\ Test for phenol \\ For qualitative determination of phenol $2.0 \mathrm{~mL}$ aqueous plant sample were taken. To these extracts, $0.5 \mathrm{~mL}$ of $\mathrm{FeCl}_{3}$ solution was added. Formation of intense brown colour indicates the precipitate of phenol.}

\section{Test for flavonoid}

For qualitative determination of flavonoid, $2.0 \mathrm{~mL}$ of aqueous plant sample were taken. To these extracts, $0.5 \mathrm{~mL}$ of $\mathrm{NaOH}$ solution was added. Formation of intense yellow 
colour that become colourless on addition of few drop of diluted $\mathrm{HCl}$ indicated the presence of flavonoid.

\section{Test for cardiac glycoside}

For qualitative determination of cardiac glycoside $2.0 \mathrm{~mL}$ of aqueous plant sample were taken. To these extracts, $2 \mathrm{~mL}$ of chloroform solution was added. And add these extracts, $2 \mathrm{~mL}$ conc. $\mathrm{H}_{2} \mathrm{SO}_{4}$ solution was added. Formation of intense layer form and deep brown colour indicates the precipitate of cardiac glycoside.

\section{Test for triterpenes}

For qualitative determination of triterpenes, $2.0 \mathrm{~mL}$ of aqueous plant sample were taken. To these extracts, $0.5 \mathrm{~mL}$ of concentrated $\mathrm{H}_{2} \mathrm{SO}_{4}$ solution was added Formation of intense brown ring indicates the precipitate of triterpene.

\section{Test for saponins}

For qualitative determination of saponins, $2.0 \mathrm{~mL}$ of aqueous plant sample were taken. Addition of $20 \mathrm{~mL}$ distilled water was done along with extracts separately. The test tube was then shaken in graduated cylinder for 15 minutes. The formation of intense $1 \mathrm{~cm}$ layer of foam indicated the presence of saponins.

\section{Test for tannins}

For qualitative determination of tannin, $2.0 \mathrm{~mL}$ of aqueous plant sample were taken. To these extracts, $0.5 \mathrm{~mL}$ of $\mathrm{FeCl}_{3}$ solution was added. Formation of intense brownish green colour indicates the precipitate of tannin.

\section{Test for carbohydrate}

For qualitative determination of carbohydrate, $2.0 \mathrm{~mL}$ of aqueous plant sample were taken. To these extracts, $0.5 \mathrm{~mL}$ of $\mathrm{H}_{2} \mathrm{SO}_{4}$ solution was added. And these extracts, $2 \mathrm{~mL}$ of Molisch reagent was added. Formation of intense violet ring indicates the precipitate of carbohydrate.

\section{Test for phlobatannins}

For qualitative determination of phlobatannine $2.0 \mathrm{~mL}$ of aqueous plant sample were taken. To these extracts, $2 \mathrm{~mL}$ of $1 \% \mathrm{HCl}$ solution was added and it was then kept for boiling in water bath. Presence of phlobatannine is indicated by intense red colour precipitate.

\section{Test for alkaloids}

For qualitative determination of alkaloids $2.0 \mathrm{~mL}$ of aqueous plant sample were taken. To these extracts, $2.0 \mathrm{~mL}$ of Wagner's reagent solution was added. Formation of intense brownish colour indicates the precipitate of alkaloids.

\section{Test for steroids}

For qualitative determination of steroid $2.0 \mathrm{~mL}$ of aqueous plant sample were taken. To these extracts, $2 \mathrm{~mL}$ of chloroform solution was added. And these extracts, $2 \mathrm{~mL}$ of conc. $\mathrm{H}_{2} \mathrm{SO}_{4}$ solution was added. Formation of intense yellow with green fluorescence colour indicates the precipitate of steroid.

\section{Test for terpenoid}

For qualitative determination of terpenoid $2.0 \mathrm{~mL}$ of aqueous plant sample were taken. To these extracts, $2 \mathrm{~mL}$ of chloroform and $0.5 \mathrm{~mL}$ of concentrated $\mathrm{H}_{2} \mathrm{SO}_{4}$ was added. Formation of intense reddish-brown colour indicates the precipitate of terpenoid.

\section{Test for reducing sugar}

For qualitative determination of reducing sugar, $2.0 \mathrm{~mL}$ of aqueous plant sample were taken. To these extracts, $2 \mathrm{~mL}$ of Fehling A and Fehling B solution was added and boiled for 5 minutes. Formation of intense orange red colour indicates the precipitate of reducing sugar.

\section{Test for protein}

For qualitative determination of protein $2.0 \mathrm{~mL}$ of aqueous plant sample were taken. To these extracts, $2.0 \mathrm{~mL}$ of Ninhydrin reagent and $2.0 \mathrm{~mL}$ were added, and boiled for 5 to 10 minutes in boiling water bath. Formation of intense dark purple colour indicates the precipitate of protein.

\section{IN VITRO DEREMINATION OF ANTIBACTERIAL ACTIVITY OF AQUEOUS PLANT EXTRACT FROM COUSTUS IGNEUS Qualitative test agar well diffusion method (Indian pharmacopoeia, 2007).}

The colonies of the organism from overnight grown standard cultures of Escherichia coli ATCC 25922 and Staphylococcus aureus ATCC 6538 were picked up with inoculating loop and suspended in $3.0-4.0 \mathrm{~mL}$ of sterile saline. This was further adjusted to $0.5 \mathrm{McF}$ arland's standard and used as inoculum for assay. Sterile muller nutrient agar was mixed with $1.0 \mathrm{~mL}$ of bacterial inoculum and poured into sterile petri plate. The petri plates were poured on the level surface and allowed to solidify. Four wells were punched in each using sterile cork borer each of $8 \mathrm{~mm}$ in diameter at equivalence $100 \mu \mathrm{l}$ of each dilution of cold plant extract and hot extract were added to the wells. Plates were incubated at $37^{\circ} \mathrm{C}$ for 24 hours.

\section{RESULT AND DICUSSION}

\section{Phytochemical Analysis of Aqueous Extract}

Leaf powder was added to distilled water and stirred continuously for half an hour. This solution was kept at room temperature for 24 hours. The solution was then boiled at 100 to make hot extract followed by filtration through Whatman filter paper no 1 . The result of Phytochemical analysis from hot leaves extracted from Costus igneus were as shown in table 1.

All phytochemicals were present in hot leaves extract of Costus igneus except for phlobatannine, reducing sugar, steroids and flavanoid. Similar results using aqueous extract of leaves were obtained by Thiruchenduran et.al., 2017

In vitro Determination of Antibacterial Activity of Hot and Cold Aqueous Plant Extract from Coustus igneus Qualitative study of hot and cold extract of Costus igneus was done by agar well diffusion method using different dilution of hot and cold extract of Costus igneus in the range of $10 \mathrm{mg} / \mathrm{ml}$ to $100 \mathrm{mg} / \mathrm{ml}$ on standard cultures of Escherichia coli ATCC 25922 and Staphylococcus aureus ATCC 6538. The results were as displayed in table 2 for hot and cold extract.

Both hot and cold aquouse extract leaves of grider powder of Costus igneus showed no zone of inhibition against standard cultures of Escherichia coli ATCC 25922 and Staphylococcus aureus ATCC 6538 by agar well diffusion method. To compare result of antibacterial activity against test microorganism in the present study no literature and reported were available. Hence this kind of comparative study may be first reported and may serve as base line study to evaluated further by researcher in future 


\section{CONCLUSION}

Costus igneus commonly known as fiery Costus, step ladder or Spiral flag or insulin plant is native to south and central America and used for its antidiabetic property and prevent the body from disease protect mind and which prolongs the longevity of life. The phytochemical analysis method in which identified phenol, triterpene saponins, tannins, carbohydrate, alkaloids, protein, terpenoids from hot extract Costus igneus plant. The antibacterial activity of cold and hot extract does not show the zone of inhibition around the well. The result of study has justified the to use different solvent extract for determine the antibacterial activity. These phytochemical constituents are of organic in nature. Bioprocess can convert simple compound to complex compound and it uses in several medicines and therapeutics.

\section{BIBLIOGRAPHY}

[1] K. S. Vinayaka, N. Anitha and B. Mathew. (2011). Antimicrobial Efficiency of Costus igneus N. E. Br. (Costaceae). Advances in Plant Sciences; 24(1): 63-65.
[2] Ramya S. K. and Chauhan J. B. (2015). Phytochemical screening, Antimicrobial activity and Antioxidant activity of Costus igneus. European Journal of Molecular Biology and Biochemistry; 2(2): 93-96.

[3] Rao B. N. , Goud G. R. , DR. E. Sujatha ,Kumari S. (2016). Phytochemical analysis and antimicrobial activity of Costus igneus (Insulin plant) leaf extract. International Journal of Biology, Pharmacy and Allied Science (IJBPAS); 5(6):1207-1214.

[4] S. Thiruchenduran, K. U. Maheshwari, TNVKV Prasad, B Rajeswari and WJ Suneetha. (2017). UV-Vis scanning coupled with PCA as an alternative method for phytochemical screening of natural products- Costus igneus leaf metabolites. Journal of Pharmacognosy and Phytochemistry; 6(1): 411-416.

[5] S. Vasantharaj, S. Sathiyavimal and N. Hemashenpagam. (2013). Antimicrobial potential and screening of antimicrobial compounds of Costus igneus using GC-MS. International Journal of Pharmaceutical Sciences and Research; 4(5): 1815-1819.

Table1: Phytochemicals from hot extract leaves of Costus igneus

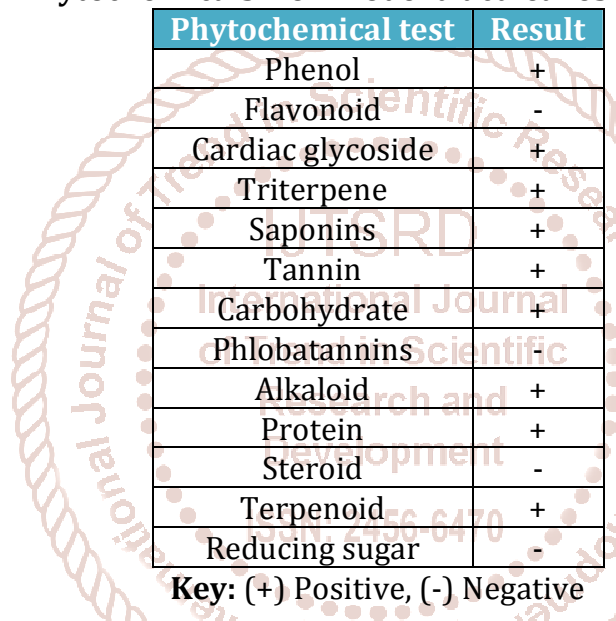

Table2: Determination of antibacterial activity by aqueous extract of Costus igneus leaves

\begin{tabular}{|c|c|c|c|c|c|c|c|c|c|c|c|}
\hline Organism & Plant extract & \multicolumn{10}{|c|}{ Concentration of plant extract $(\mathrm{mg} / \mathrm{ml})$} \\
\hline & & 10 & 20 & 30 & 40 & 50 & 60 & 70 & 80 & 90 & 100 \\
\hline & & \multicolumn{9}{|c|}{ Zone of inhibition ( $\mathrm{mm}$ ) } & \\
\hline \multirow{2}{*}{ Escherichia coli ATCC 25922} & Cold & - & - & - & - & - & - & - & - & - & - \\
\hline & Hot & - & - & - & - & - & - & - & - & - & - \\
\hline \multirow[t]{2}{*}{ Staphylococcus aureus ATCC 6538} & Cold & - & - & - & - & - & - & - & - & - & - \\
\hline & Hot & - & - & - & - & - & - & - & - & - & - \\
\hline
\end{tabular}

Key: (-) No growth 